\title{
O bibliógrafo digital: questões sobre a materialidade do livro no século XXI
}

Ana Elisa Ribeiro

\author{
Doutora em Linguística Aplicada pela \\ Universidade Federal de Minas Gerais (UFMG). \\ Professora do Centro Federal de Educação \\ Tecnológica de Minas Gerais (CEFET-MG)
}

http://dx.doi.org/10.1590/1981-5344/3236

Este artigo discute as materialidades do livro e a bibliofilia em tempos de devices digitais. Oferecendo mais questionamentos do que respostas, tratamos aqui, com base em ocorrências do presente quanto ao livro literário, das implicações de (não) definirmos o que seja um livro, assim como do valor no cenário de livros digitais e impressos. A coleção de livros, espaço e tempo, as estantes virtuais do bibliófilo evanescente fazem parte deste cenário no século XXI. Colocamos em pauta a figura do bibliógrafo digital, um leitor ainda por se conhecer.

Palavras-chaves: Livro impresso. Livro digital. Bibliofilia. Bibliografia.

\section{The digital bibliographer: issues about book technologies in the $21^{\text {st }}$ century}

This paper discusses the bibliophily and the materialities of the book in digital devices age. Giving more questions than answers and based in real ocurrencies about literary books, here we discuss the implications of (in)definitions about what is a book, as well as the symbolic value of digital and pressed books. Book colections, space and time, the virtual bookcases of evanescent bibliophile are part of this scenario in the 21th century. We design and focuse the digital bibliographer, yet an unknown type of reader.

Keywords: Paper book. Digital book. Bibliophilia. Bibliography. 


\section{0 que é um livro? Implicações e implicâncias}

Este trabalho convida a uma reflexão sobre o leitor e os livros na era das tecnologias digitais, propondo um trajeto que parta de nosso contexto histórico em relação aos computadores e à internet, passe pelas reconfigurações das práticas de consumo e de leitura dos livros em novos devices, sem necessariamente valorá-las como piores ou desvantajosas, terminando por reafirmar os livros como objetos - diversos em suas materialidades - de uma rede sociotécnica profundamente ligada ao humano. Não se trata de um trabalho definitivo e afirmativo, senão de um ensaio cujos questionamentos são mais potentes do que eventuais respostas (sempre um tanto proféticas e passíveis de erro). A ideia de um "bibliógrafo digital" se articulará às questões sobre o "gesto bibliográfico", sob a inspiração de Giulia Crippa (2016). E iniciaremos pelo passado recente.

Há poucas décadas, vimo-nos - nós, grafocêntricos e herdeiros das tecnologias do livro impresso - confrontados com novos modos de ler, de escrever, de publicar, de consumir textos, de fazer circular informação e conhecimento ou, simplesmente, de fazer circular textos. Embora muitos estudiosos tenham se dedicado à questão da materialidade do livro, isto é, do produto gerado a partir de algum processo de edição, impressão e/ou "apresentação", outros tantos percebem que a digitalização do processo de edição/editoração, desde o processo mesmo que envolve a criação, encontra-se em estágio avançado e balístico ${ }^{1}$. Que livros, hoje, não começam já a ser escritos no computador?

No Brasil, podemos falar em tecnologias digitais da informação e da comunicação, com alcance mais amplo, a partir dos anos 1980; dos anos $1990^{2}$, considerando-se a internet e as interfaces amigáveis de navegação. Editores de texto, de imagem e programas para diagramação equipam progressivamente as máquinas, primeiro entre os especialistas e depois para faixas mais amplas da população. O fato é que os modos mecânicos de produzir livros, como a tipografia ${ }^{3}$, foram cedendo espaço a formas mais ágeis e menos custosas de escrever, diagramar e imprimir, ou mesmo de publicar e fazer circular os textos.

Para pensar em um espaço enunciativo específico - e para mim especial -, a literatura, tomemos como exemplo o desejo de publicação de um(a) poeta nascente. São comuns as histórias de poetas, hoje conhecidos(as), que começaram suas carreiras imprimindo poemas em livretos manufaturados, copiados por meio de equipamentos conhecidos como mimeógrafos - hoje, peças de museu -, grampeados ou colados a mão, distribuídos pelo(a) próprio(a) artista em espaços como bares e

1 Roger Chartier (1998; 1998a; 2001; 2002; 2014) talvez seja o mais conhecido historiador do livro entre nós. O autor toca nos temas relativos ao texto eletrônico e à digitalização, em alguns momentos de sua obra. Já Robert Darnton, especialmente em Darnton (2010), discorre longamente sobre a questão da digitalização das obras impressas.

2 Comumente, considera-se o ano de 1995 como o da popularização do computador e das interfaces gráficas para acesso à web, no Brasil.

$3 \mathrm{Em}$ Belo Horizonte, por exemplo, temos uma única tipografia, a do Matias, ainda atendendo comercialmente, no bairro de Santa Efigênia. Ver: <http://www.tipografiamatias.com.br/>. Acesso em: 5 dez. 2016. 
restaurantes. São dezenas de narrativas sobre livros iniciantes feitos com xerox, grampo e disposição, dinheiro próprio e venda corpo-a-corpo. Ferreira Gullar, consagrado poeta brasileiro falecido em $2016^{4}$, deu início à sua trajetória com um livro "de autor", mais tarde renegado.

As questões da materialidade estão tão implicadas nas trajetórias dos autores - sejam eles literatos ou não - que é impossível desviarmonos das questões que se colocam, já há décadas. Se um livro passa a existir, nasce, com ele, um autor/escritor ; se um livro chega ao seu leitor, cumpre-se um trajeto desejado por muitos; se um livro existe como impresso, em tese, trava-se uma batalha para que efetivamente circule, encontre leitores, seja vendido, seja apreciado ${ }^{6}$; se um livro existe como programa ou aplicativo, trava-se uma outra batalha de distribuição e consumo, mais monitorada, mas não menos difícil.

Não basta pensar os livros como se fossem existências autônomas, por mais que eles possam sobreviver a séculos de relativo abandono, sem morrer e sem parar de respirar, apenas hibernando em estantes. Os livros fazem parte desta rede sociotécnica que não me atreverei a discutir profundamente. Os livros são existências, impressas ou digitais, autossuficientes como objeto ou, mais recentemente, dependentes de devices, que nos conectam uns aos outros, costuram relações e alteram sentidos na existência humana. Não basta pensá-los como se fossem secções de um mundo inanimado, como poderíamos, desde há muito tempo e um tanto inadvertidamente, descrevê-los. É preciso pensá-los como integrantes desta grande interação de que todos fazemos parte, já que os livros encapsulam nossas ideias, boas ou ruins, atuando como sinapses, quando lidos, relidos, discutidos, resenhados, mal falados, copiados, citados, colecionados, doados, queimados, reimpressos, esquecidos para serem relembrados ${ }^{7}$. Não são híbridos de humano e objeto, mas são objetos de mobilização, interação e jogos de poder ${ }^{8}$.

A materialidade dos livros traz implicações não apenas para sua própria forma de existir - em papel, tal ou qual, com lombada, orelhas, capas, ou digital, mostrado em um equipamento de dimensão $X$ ou $Y$, tal ou qual capacidade de memória ou processamento, e assim... -, mas para nossa existência humana, profissional, social. Discussões econômicas de amplo escopo são motivadas pela questão, aparentemente banal: 0 que é um livro ${ }^{9}$ E sabemos: um livro precisa ser definido. Talvez soe antipoético para alguns, mas trata-se de uma questão prática, afinal.

40 poeta maranhense, residente no Rio de Janeiro, faleceu às $10 \mathrm{~h}$ da manhã do dia 4 de dezembro de 2016 . Ver, por exemplo: <http://www1.folha.uol.com.br/ilustrada/2016/12/1838326-poeta-ferreira-gullarmorre-aos-86-anos-no-rio.shtml>. Acesso em> 4 dez. 2016.

5 Consideramos aqui que a literatura esteja intrinsecamente ligada à existência do livro. No entanto, sabemos de sua preexistência e de sua resistência oral. No século XXI, ela persiste também no movimento amplo dos saraus, em rede com a existência dos livros.

6 Essa "batalha" é estudada por John Thompson para livros trend, isto é, best-sellers não literários. Ver Thompson (2013).

${ }^{7}$ Bayard (2007) trata de como os livros fazem parte de nossa sociedade ao ponto de podermos falar deles sem os termos lido.

8 Para uma introdução à teoria ator-rede, por exemplo, leia-se Latour (1994).

9 Vimos nos arriscando nesta questão em Ribeiro (2011; 2012). Em dezembro de 2016/ março de 2017, participamos de um evento chamado "O que é um livro? Resistências", a convite dos organizadores, na Universidade Federal de Minas Gerais. Nessa oportunidade, constatou-se a diversidade do que pode ser um livro, segundo muitos participantes. Sem conclusões estáveis. 
Se não sabemos mais definir um livro, como pagaremos impostos e taxas sobre devices que carregam bibliotecas inteiras? ${ }^{10} \mathrm{Em} \mathrm{2015}$, a União Europeia debateu impostos e taxas quanto aos e-books de maneira veemente. A França, por exemplo, fez uma campanha para igualar livros impressos e eletrônicos, com o intuito de pagar as mesmas taxas sobre ambos (já que impressos pagam menos impostos). A Itália entrou na mesma batalha. Um recurso interessante, usado pela Itália, foi passar a definir livro como qualquer produto que apresentasse número de ISBN (International Standard Book Number). Esse mesmo número internacional acaba de ser desobrigado pela Câmara Brasileira do Livro entre os concorrentes ao prêmio Jabuti de livro eletrônico para literatura infantil, isto é, essa categoria, aberta em 2016, dispensa a apresentação de obras digitais sob ISBN.

E como buscaremos textos, trechos, informações, poemas, gráficos em dispositivos que antes escondem do que apresentam? Quanto cobraremos para que um leitor consuma um livro? ${ }^{11} \mathrm{E}$ como precificaremos? Em que se transforma o "preço de capa", sem as capas? Invadiremos a interação entre leitor e texto? Quem é o autor de uma obra que se "baixa"? E do que ele viverá, se contarmos por downloads, views, em centavos?

Das grandes questões econômicas, que obrigam que países definam, política e estrategicamente, o que seja um livro - tudo o que tiver ISBN? Ou objetos de papel, com capas e mais de 49 páginas? ${ }^{12}$-, passamos a questões de foro íntimo: gosto mais disto do que daquilo. Do cheiro à capacidade de armazenamento, que argumentos são estes? Mas, principalmente, das espertezas inerentes às práticas de letramento ${ }^{13}$ : os usos vão se diversificando conforme a natureza do livro \& a natureza do livro pode ir se diversificando conforme as práticas de leitura. Dos livros do coração ${ }^{14}$ aos livros de uso ou consulta, em um espectro de interações que independe, em larga medida, de nossas discussões apegadas a esta ou àquela tecnologia. De todo modo, pensar e repensar o livro decorre de nossas inquietações de natureza variada - afetivas, editoriais, profissionais, culturais... -, trazendo também implicações para a pesquisa e o mercado editorial.

10 Ver notícias em: <http://www.publishnews.com.br/materias/2015/03/04/80889-essa-pantufa-de-oncinhanao-e-um-livro>. Acesso em: $6 \mathrm{dez} .2016$.

11 As lojas de livros eletrônicos podem monitorar se esses livros são mesmo lidos, quantas páginas, por quanto tempo. E essa medida define se e quanto se pagará de direito ao autor.

12 Esta é a definição/padronização da Unesco (United Nations Educational, Scientific, and Cultural Organization), ainda vigente. Foi publicada em 1964. Ver: <http://portal.unesco.org/en/ev.phpURL_ID=13068\&URL_DO=DO_TOPIC\&URL_SECTION=201.html>. Acesso em: 4 dez. 2016.

13 Letramento é um conceito muito debatido nos campos da Educação e da Linguística Aplicada. No Brasil, a discussão existe desde a década de 1980 e teve impacto sobre políticas públicas educacionais. Atribui-se a importação do conceito a Mary Kato, na década de 1980. As autoras brasileiras referência no tema são Magda Soares (UFMG) e Angela Kleiman (Unicamp). A discussão desdobrou-se em várias, incluindo-se a relação com tecnologias digitais. Ver, por exemplo: Soares (2002; 2004), Kleiman (1995), Coscarelli e Ribeiro (2005).

14 A expressão é tomada de empréstimo às professoras Roberta Manuela Andrade (UECE) e Erotilde Silva (Unifor), pesquisadoras de livros vendidos em bancas e colecionados por milhares de leitores. Alguns de seus trabalhos foram publicados nos anais do Encontro Nacional da Intercom, Sociedade Brasileira de Estudos Interdisciplinares da Comunicação. Ver, por exemplo, Andrade e Silva (2014). 


\section{0 bibliógrafo digital}

O campo das Letras raramente se põe a pensar sobre a organização dos livros entre si, geralmente elegendo a reflexão sobre eles internamente. Menos que isso: nos textos que vão neles, mais do que neles. Normalmente, estamos entretidos, analisando obras ou pensando em como escrevê-las e lê-las (interpretá-las). O problema da bibliografia parece-nos menos próximo do que o da bibliofilia. O escritor italiano Ítalo Calvino (2010, p. 13) diz, sobre as coleções, assim como dos diários, que são: "a necessidade de transformar o escorrer da própria existência numa série de objetos salvos da dispersão (...)". E dar sentido aos livros tem sido uma intenção completamente rearticulada, nos dias que correm.

A bibliografia, discutida há tempos, está em Crippa (2016) transformada em um convite ao repensar. De prática disciplinadora à criação de novos paradigmas, é importante reconhecer os movimentos do universo da informação e do livro como questões também humanas. Tão humanas que são alçadas ao "gesto". Deixam de ser apenas "uma descrição de materiais entregues ao bibliógrafo sem discernimento (...)" (CRIPPA, 2016, p. 26), ou uma seleção neutra, para ser um encontro entre bibliógrafos e usuários, sem esquecer que "o digital representa uma mudança radical da própria natureza dos documentos e dos instrumentos de catalogação (...)" (CRIPPA, 2016, p. 27).

Se a história da leitura e dos livros, em seu início, toma como fontes de pesquisa justamente as listas e os catálogos, logo obtém resultados insuficientes para responder a certas questões de interesse humano: mas o que fazem os leitores com estes livros? Como os leem, afinal? E daí nasce a história das práticas de leitura, esclarecedora porque focaliza justamente o "gesto" que não se pode recompor ou vislumbrar apenas com base no catálogo (DARNTON, 2010).

No entanto, o gesto bibliográfico atual, conforme Crippa (2016), não dá conta das novas realidades tecnológicas. Para a autora, é necessária uma mudança estrutural, incluindo-se a reinvenção da "ordem do futuro". "Não mais adaptação, mas criação de novos paradigmas para as práticas bibliográficas" (CRIPPA, 2016, p. 37). Impossível esquivarmo-nos do livro digital e das bibliotecas também digitais, sem estantes, sem paredes, sem etiquetas, por onde leitores ou usuários circulam um tanto erraticamente, percebendo ou não que precisam de ajuda.

Quanto mais nos precipitamos sobre este mundo das tecnologias digitais, mais pensamos, especialmente os linguistas, que cada pessoa precisa ser um tanto bibliógrafa, letrada "informacional", curadora, seletiva, capaz do gesto bibliográfico em sua trilha, cada vez mais pessoal, de leitura e fruição dos documentos. A biblioteca é cada vez mais mental e menos espacial ou geográfica, se pensarmos que um dos argumentos para a ascensão do livro digital é que ele "ocupa menos espaço" (ou terreno mesmo) e que alguém pode ter milhares de livros em um device de alguns gramas. No entanto, por quanto tempo? Até quando e por meio de que suporte? É a pergunta que incomoda o bibliófilo, talvez 
também o bibliógrafo, preocupados ambos em organizar, criar trilhas experienciáveis, dar sentido a uma coleção.

Se teremos mil ou dois mil livros que não podemos ver juntos, ao mesmo tempo, que espécie de organização eles devem ter para que possam ser vistos e relembrados? Se o aspecto gráfico-espacial não é mais necessário ou vantajoso, por onde começar? E até: por onde trilhar? Se as trilhas têm pontas soltas, diversas, onde começam e onde terminam? O perímetro de uma tela acomoda quantas coleções? Que sujeitos serão capazes de se apropriar, de fato, do que não for descartável?

O bibliógrafo digital tem seu acervo mais velado do que revelado; precisa de sua própria memória para conseguir encontrar os fios que o levam aos textos ou aos livros que deseja ler. Tratará de guardar o que Ihe importa em um equipamento que se desliga, tornando sua biblioteca em um ícone fora do campo de visão. Uma biblioteca apagada, mas em potência, ao menos até a próxima incompatibilidade operacional. 0 bibliógrafo digital lembra um pouco o conto de João e Maria, tradicionalmente narrado às crianças: é preciso deixar migalhas para encontrar de novo o caminho. Rememorando a história, perguntamos: deu certo? No caminho entre o leitor e o livro, pode haver o imprevisto, o imponderável e certa dose de inocência. As migalhas do bibliografo digital precisam ser mais efetivas. Retomando Calvino (2010), salvar da dispersão é a missão deste leitor, assim como construir trilhas e estratégias de retomada mais seguras.

\section{Livros digitais, impressos e a literatura, por exemplo...}

Normalmente, a experiência com livros literários, por exemplo, não é descartável. Talvez esse seja um critério, inclusive, para identificar a literariedade de uma obra. Da obra que não termina de ser relida, sempre chamada ao presente, fazendo sentido conforme a experiência de linguagem que o leitor vive, à obra que precisa estar exposta em um espaço de coleção, de memória, de atualização. Uma obra que se empresta, mas que se deseja ter de volta. Uma obra mais que livro, um verdadeiro ritual, desde a sua criação até a sua infindável leitura, por um ou por muitos.

Desde a sua concepção, o livro literário é envolto em rituais. A gestão da autoria, analisada em Maingueneau (2014) e exemplificada em Pereira (2017), que trata do escritor brasileiro Milton Hatoum, é feita desde a escrita do texto, passando por seu processo editorial e por sua difusão, com a mediação de uma editora e de muitas outras instituições e redes editoriais. Os rituais podem ser especializados em "ritos genéricos editoriais", conforme proposta de Salgado (2016), inspirada em Maingueneau. E todos eles dizem respeito ao que a humanidade atribui ao livro e a si mesma em relação a ele. O lançamento15, por exemplo, de um

15 O lançamento de livros com a presença do autor é uma invenção, segundo Hallewell (2005), de Carlos Ribeiro, dono da livraria Teixeira, em São Paulo, na década de 1950. Há uma controvérsia sobre o assunto, já que Erico Verissimo afirma que os irmãos Saraiva fizeram isso antes, na década de 1940. Há registro, 
livro impresso, é um evento palpável, onde o autor encena sua performance nas assinaturas, dedicatórias e presença. Já o "lançamento" de um livro digital desveste-se de quase tudo o que um livro impresso carrega de simbólico e de experiência material para tornar-se uma espécie de encontro fortuito. O que é um livro com um autógrafo? Quanto de sentido há nisso? Quanto tempo se passará até que aquele livro deixe de ser um objeto qualquer e torne-se a prova de uma experiência?

Quanto à experiência digital: se meu livro pode ser apagado de meu device a qualquer momento, descobrirei logo a decadência da posse e a ascensão dos "termos de uso" ou da "licença". O livro não é exatamente meu; trata-se de uma possibilidade de leitura, em potência mesmo. Com isso, qualquer biblioteca será um instante apenas na dinâmica linha do tempo dos livros digitais semoventes.

\section{Considerações provisórias}

O gesto bibliográfico está no bibliófilo digital entre as pastas amarelas das interfaces gráficas; em estantes virtuais que só mostram o que cabe em 7 ou 10 polegadas; nas listas ou nas capas das obras que ele consegue comprar, por prazo desconhecido quanto aos usos ou quanto à duração/compatibilidade de seu device. O gesto diante do fato de que "também as cousas participam de nossa vida". O "gesto de ferina intenção", na expressão da escritora mineira Henriqueta Lisboa, que toque os livros, as rosas e qualquer outro objeto de nosso "íntimo domínio" e de nosso "intransferível patrimônio", que nos servem não apenas para adquirir, colecionar, organizar, mas também para nos identificar com o outro e com a humanidade. Supérfluos? Sabe a sociologia da literatura16 que livros têm impacto sobre nossas vidas.

O que é um livro, hoje? (Daremo-nos o tempo de um parágrafo). Um possível objeto dentro de outros objetos. Como sempre? Ou sequer podemos dizer que seja um objeto? Um software que "roda" sobre uma base hardware? A alma sobre um corpo físico (a eterna proposta kantiana, segundo Chartier, 2014)? Ou nosso tradicional conhecido tinta-e-papel, elementos físicos geralmente indissociáveis, eternamente inscritos um no outro17, a despeito de o texto mesmo/sua leitura ser ainda uma outra questão?

Esses questionamentos tocam o leitor, uma vez que as mudanças no objeto que ele manipula ou com que lida fazem-no reorientar ou reconfigurar suas práticas. O bibliógrafo digital não é, ele mesmo, digital, como a expressão pode levar a crer, mas é o dono do gesto bibliográfico na era das tecnologias digitais, o ativo consumidor de textos que circulam sem tanto compromisso com um ou outro objeto. Ativo, como sempre, frise-se, mas agora demandado a organizar seu acervo sem vê-lo por completo, sem a certeza, sequer, de que ele estará hoje onde estava

ainda segundo Hallewell, de lançamentos com a presença do autor na livraria José Olympio, em 1934, mais precisamente com o escritor José Lins do Rego.

16 Ver, por exemplo, Sapiro (2016).

17 Papéis de tipos diferentes aceitam tintas diferentes de maneiras diversas. 
ontem. O ambiente digital provoca um senso de organização mais virtual e um gesto de busca mais informado. É preciso navegar; e navegar orientado.

O livro já foi um objeto autossuficiente. Ou um objeto em si, sem grandes descolamentos entre sua materialidade e as possibilidades de seu conteúdo. Pensando assim, é parecido com as possibilidades do livro digital, por exemplo, que é promessa à espera de um clique. O livro passa a ser uma potência, e ubíqua, em arquivos que esporulam ou que se replicam feito vírus, sem controle? Sem sentido? Se nos lembrarmos que os sentidos sempre foram dados na interação obra-leitor, não teremos tantos problemas em admitir que o livro seja, hoje, uma espécie de dobra sob um objeto físico não exclusivo/dedicado. O leitor e seus gestos é que precisam estar aptos a desdobrar - a si nos livros e aos livros.

O poema de Henriqueta Lisboa, publicado em 1982, no livro Pousada do ser, se antecipa à era das tecnologias digitais no Brasil. Nossas questões sociotécnicas ecoam na certeza do eu lírico de que "também as cousas participam / de nossa vida". Entre elas, nominalmente, o livro. E essas cousas nos identificam, nos unem ou nos separam. "Um trecho musical que nos devolve / a horas inaugurais" é exemplo de nossa potência virtual. É preciso ir buscar na memória o lugar das experiências. "A lembrança / de outra lembrança mais longínqua" se parece com o mise-en-abyme a que já estamos acostumados quando nos embrenhamos pelas redes digitais.

Mesmo que tudo isso pareça supérfluo, a poeta questiona: "que tenho a ver contigo / se não leste o livro que li", esperando a formação de um patrimônio intransferível mas compartilhável, o patrimônio, por exemplo, dos textos que se disponibilizam, que nos formam, que nos tornam em pessoas com repertórios distintos, embora sempre em atualização, reconfiguração e movimento. O livro digital vem participar desta rede, tão supérflua quanto importante, tão humana quanto máquina, tão componedora de nossas práticas quanto qualquer outra coisa que conosco interaja.

\section{Do supérfluo}

Também as cousas participam

de nossa vida. Um livro. Uma rosa.

Um trecho musical que nos devolve

a horas inaugurais. O crepúsculo

acaso visto num país

que não sendo da terra

evoca apenas a lembrança

de outra lembrança mais longínqua.

O esboço tão-somente de um gesto

de ferina intenção. A graça

de um retalho de lua

a pervagar num reposteiro

A mesa sobre a qual me debruço

cada dia mais temerosa 
de meus próprios dizeres.

Tais cousas de íntimo domínio

talvez sejam supérfluas.

No entanto

que tenho a ver contigo

se não leste o livro que li

não viste a rosa que plantei

nem contemplaste o pôr-do-sol

à hora em que o amor se foi?

Que tens a ver comigo

se dentro em ti não prevalecem

as cousas - todavia supérfluas -

do meu intransferível patrimônio?

Este trabalho buscou uma reflexão sobre os gestos e as práticas hoje disponíveis ao leitor, em um cenário de turbulências e movimentos, ou de reconfigurações, que envolvem a leitura, a escrita e as tecnologias do livro. O bibliógrafo digital vem se somar aos demais personagens desta rede sociotécnica que envolve os objetos de ler em sua íntima relação com a humanidade.

\section{Referências}

ANDRADE, Roberta Manuela B.; SILVA, Erotilde H. O Que é um Romance Inesquecível? Os Processos de Apropriação Cultural dos Livros do Coração. Intercom - Sociedade Brasileira de Estudos Interdisciplinares da Comunicação. XXXVII Congresso Brasileiro de Ciências da Comunicação. Anais... - Foz do Iguaçu, PR, p.1-15, 2 a 5 set. 2014. Disponível em: <http://www.intercom.org.br/papers/ nacionais/2014/resumos/R9-03281.pdf>. Acesso em: 2 dez. 2016.

BAYARD, Pierre. Como falar dos livros que não lemos? Tradução de Rejane Janowitzer. Rio de Janeiro: Objetiva, 2007.

CALVINO, Ítalo. Coleção de areia. Tradução de Maurício Santana Dias. São Paulo: Companhia das Letras, 2010.

CHARTIER, Roger. A ordem dos livros: leitores, autores e bibliotecas na Europa entre os séculos XIV e XVIII. 2. ed. Tradução de Mary Del Priore. Brasília: Editora Universidade de Brasília, 1998.

CHARTIER, Roger. A aventura do livro: do leitor ao navegador. Tradução de Reginaldo de Moraes. São Paulo: UNESP, 1998a. (Prismas)

CHARTIER, Roger. Cultura escrita, literatura e história: Conversas de Roger Chartier com Carlos Aguirre Anaya, Jesús Anaya Rosique, Daniel Goldin e Antônio Saborit. Porto Alegre: ARTMED, 2001.

CHARTIER, Roger. Os desafios da escrita. Tradução de Fulvia M. L. Moretto. São Paulo: UNESP, 2002. 
CHARTIER, Roger. A mão do autor e a mente do editor. Tradução de George Schlesinger. São Paulo: Editora da Unesp, 2014.

COSCARELLI, Carla; RIBEIRO, Ana Elisa. Letramento digital. Aspectos sociais e possibilidades pedagógicas. Belo Horizonte: Autêntica, 2005.

CRIPPA, Giulia. Entre arte, técnica e tecnologia: algumas considerações sobre a bibliografia e seus gestos. InCID: R. Ci. Inf. e Doc., Ribeirão Preto, v. 7, n. esp., p. 23-40, ago. 2016.

DARNTON, Robert. A questão dos livros. Passado, presente e futuro. Tradução de Daniel Pellizzari. São Paulo: Companhia das Letras, 2010.

KLEIMAN, Angela B. (Org.) Os significados do letramento: uma nova perspectiva sobre a prática social da escrita. Campinas, SP: Mercado de Letras, 1995. (Coleção Letramento, Educação e Sociedade)

LATOUR, Bruno. Jamais fomos modernos. Ensaio de antropologia simétrica. Tradução de Carlos Irineu da Costa. Rio de Janeiro: Editora 34, 1994. (Coleção Trans)

MAINGUENEAU, Dominique. Discurso literário. 2 ed. Tradução de Adail Sobral. São Paulo: Contexto, 2014.

PEREIRA, Claudia Maria de Serrão. O processo de constituição do livro Dois Irmãos: uma análise da paratopia criadora de Milton Hatoum. 2017. Dissertação (Mestrado em Literatura). Universidade Federal de São Carlos, São Carlos, 2017.

RIBEIRO, Ana Elisa. Ler na tela - O que é, hoje, um livro? In: MARTINS, Aracy Alves; MACHADO, Maria Zélia Versiani; PAULINO, Graça; BELMIRO, Celia Abicalil. (Org.). Livros \& telas. Belo Horizonte: Editora da UFMG, 2011, v. 1, p. 93-106.

RIBEIRO, Ana Elisa. O que é e o que não é um livro: materialidades e processos editoriais. Fórum Linguístico, Florianópolis, v. 9, n. 4, p. 333341, out./dez. 2012. Disponível em: <https://periodicos.ufsc.br/index.php/forum/article/view/1984-8412.

2012v9n4p333/24236>. Acesso em 2 dez. 2016.

RIBEIRO, Ana Elisa. Questões provisórias sobre literatura e tecnologia: um diálogo com Roger Chartier. Estudos de Literatura Brasileira Contemporânea, n. 47, p. 97-118, jan./jun. 2016.

SALGADO, Luciana Salazar. Ritos genéticos editoriais: autoria e textualização. Bragança Paulista, SP: Margem da Palavra, 2016.

SAPIRO, Gisèle. La sociología de la literatura. Buenos Aires: Fondo de Cultura Económica, 2016.

SOARES, Magda. Novas práticas de leitura e escrita: letramento na cibercultura. Educação e Sociedade, Campinas, v.23, n.31, p. 143-160, dez. 2002.

SOARES, Magda. Letramento: um tema em três gêneros. 2 ed. Belo Horizonte: Autêntica, 2004. 
THOMPSON, John B. Mercadores de cultura: o mercado editorial no século XXI. Tradução de Alzira Allegro. São Paulo: Editora da Unesp, 2013. 